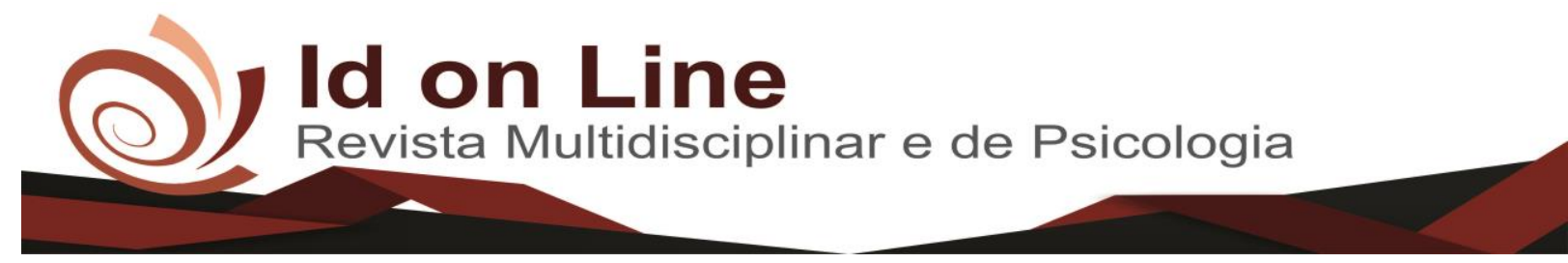

Artigo

\title{
Qualidade de Vida no Trabalho: um Estudo Bibliométrico da Pesquisa em Português
}

Maria Jaqueline da Silva Mandú ${ }^{1}$, Jorge da Silva Correia Neto², Marcílio Ferreira de Souza Júnior ${ }^{3}$

Resumo: Nas últimas décadas as pesquisas sobre qualidade de vida no trabalho (QVT) têm-se ampliado, pois para que os colaboradores sejam mais produtivos, é preciso melhor conhecer seus anseios e necessidades. A QVT é ainda um dos assuntos mais discutidos nas ciências administrativas, por isso decidiu-se realizar este estudo bibliométrico com o objetivo de verificar como as publicações científicas têm abordado esse relevante tema. Para tanto, foram analisados artigos escritos em português e indexados à base de dados do Portal de Periódicos da CAPES, publicados de 2007 a 2017. Dentre as contribuições desse estudo destacam-se a identificação dos construtos mais relacionados com QVT, as revistas que mais publicam sobre o tema e os autores mais citados, consubstanciando o panorama da produção científica da área.

Palavras-chave: Qualidade de Vida no Trabalho; QVT; Estudo Bibliométrico; Produção Científica.

\section{Quality of Work Life: a Bibliometric Study of Portuguese Research}

Abstract: In the last decades research on quality of work life (QWL) has expanded, because to improve employees' productivity, it is better to know their desires and needs. QWL is still one of the most discussed subjects in the administrative sciences, so it was decided to carry out this bibliometric study in order to verify how scientific publications have approached this relevant topic. In order to do so, articles written in Portuguese and indexed to the CAPES Portal of Periodicals database, published from 2007 to 2017, were analyzed. Among the contributions of this study are the identification of the most QWL-related constructs, the journals that have more published articles on the subject and the most cited authors, drawing an overview of the scientific production of the area.

Keywords: Quality of Work Life; QWL; Bibliometric Study; Scientific production.

\footnotetext{
${ }^{1}$ Mestranda em Administração Pública pela UFRPE. Possui graduação em Letras pela Faculdade de Formação de Professores de Serra Talhada (2009) e especialização em Letras e Literatura pela Faculdade de Formação de Professores de Serra Talhada (2012). Atualmente é Técnica em Secretariado da Universidade Federal Rural de Pernambuco. Tem experiência na área de Letras e Administração. jaquelinesilv@ hotmail.com;

2 Professor adjunto da Universidade Federal Rural de Pernambuco desde 2006 e atualmente atuando no bacharelado em Administração Pública a distância pela UAB-UFRPE. Graduado em Administração pela UFPE (2003), especialista em Docência do Ensino Superior pela FADEPE (2007), mestre em Administração pela UFPE (2005) e doutor em Administração pela UFPE (2014). Desenvolve pesquisas nas áreas de sistemas de informação e redes sociais. Membro fundador do grupo de pesquisa CNPq - RedeTECNES - Informação, Educação e Tecnologia Colaborativa em Saúde. Tem experiência profissional nas áreas de Informática e Administração, e docente em sistemas de informação, economia, administração geral e logística. Membro permanente dos Programas de Pós-Graduação em Informática Aplicada (PPGIA) e em Administração Pública (PROFIAP).jorgecorreianeto@gmail.com;

${ }^{3}$ Possui Doutorado em Administração (linha de Tecnologia da Informação) pela Universidade Federal de Pernambuco (UFPE). Atualmente é Professor do Instituto Federal de Alagoas (IFAL) no Campus Maceió. Atuou por 09 anos como Analista de Sistemas da Secretaria de Estado da Saúde de Alagoas (SESAU). Tem experiência na área de Ciência da Computação, com ênfase em Engenharia de Software e Sistemas de Informação em Saúde, atuando principalmente nos seguintes temas: integração de sistemas de informação, e-Health, mobile health, arquitetura orientada a serviços (SOA) e gerenciamento de processos de negócio (BPM).marcilio@ifal.edu.br.
}

1114 Id on Line Rev. Mult. Psic. V.12, N. 40. 2018 - ISSN 1981-1179 Edição eletrônica em http://idonline.emnuvens.com.br/id 


\section{Introdução}

A temática da qualidade de vida no trabalho (QVT) não é recente, remonta à época da Revolução Industrial e da sistematização dos métodos de produção no século XVIII e XIX, quando as condições de trabalho e sua influência sobre a produtividade e a moral dos trabalhadores passaram a ser estudadas de forma científica (SANT'ANNA; MORAES, 1998). Entretanto, não deixa de ser atual, posto que o assunto nos direciona ao bem-estar das pessoas no seu ambiente profissional, cada dia mais dinâmico. Esse tema está sempre se renovando e se adaptando aos novos contextos da realidade.

A convivência humana no mundo do trabalho tem se modificado ao longo da história, com colaboradores e organizações tentando se adaptar uns aos outros, ambos com o mesmo intuito: viver bem. O equilíbrio organizacional depende do equilíbrio dos indivíduos e das relações estabelecidas entre estes e as organizações. Repensar a organização implica rever a estrutura de poder e de autoridade vigentes, a qualidade de vida dos indivíduos pertencentes à mesma, os padrões de relacionamentos interpessoais e sistemas de comunicação, entre outras questões (KANAANE, 2011). Esse mesmo autor afirma que a qualidade de vida tem relação direta com as necessidades e expectativas humanas e com a satisfação destas. Além disso, diz respeito ao bem-estar do indivíduo no ambiente de trabalho, promovido por meio de relações saudáveis e harmônicas.

Para se sustentarem, as organizações requerem recursos financeiros, materiais e tecnológicos, entre outros; contudo, esses recursos são geridos por pessoas que precisam ser valorizadas, pois sem elas a organização não existiria, são eles que a impulsionam. Essas pessoas buscam, dentro de seu ambiente de trabalho, além do sustento financeiro, alcançar objetivos pessoais, que não poderiam ser atingidos individualmente.

Para que as empresas se tornem competitivas, é necessário que seus empregados apresentem elevados níveis de produtividade. Isso torna-se evidente quando se fala de vantagem competitiva das nações, pois costuma-se utilizar como fatores avaliativos os índices de produtividade de sua mão-de-obra. Essa produtividade, por sua vez, depende de dois fatores: capacitação e motivação (GIL, 2008a).

Os trabalhadores, que podem optar por empregos no mercado de trabalho, preferem aqueles que lhes ofereçam oportunidades de utilizar suas habilidades e capacidades, que ofereçam uma variedade de tarefas, liberdade e feedback sobre o próprio desempenho 
(ROBBINS, 2009). Estudos comprovam que a retenção de colaboradores talentosos é o que gera a manutenção de clientes e esta, por sua vez, sustenta a lucratividade das organizações. Mas então como reter esses talentos? Investir na qualidade de vida no ambiente de trabalho torna-se uma possibilidade.

A QVT é um dos assuntos mais discutidos nas Ciências Sociais Aplicadas, tema este que vem ganhando espaço enquanto valor essencial dentro das práticas que visam promover o bem-estar organizacional (TAVARES; LIMACHI, 2017), daí a relevância desse estudo bibliométrico. A pesquisa bibliométrica é uma análise quantitativa das produções científicas que viabiliza a construção de um panorama de um dado domínio de conhecimento a partir das publicações em revistas ou congressos científicos (SLOMSKI et al., 2013).

Além desta introdução, o estudo é composto pelo referencial teórico, onde são apresentados conceitos inerentes ao tema abordado. Posteriormente, expõem-se os aspectos metodológicos da pesquisa, para, na sequência, apresentar a descrição e análise dos resultados. Na última seção, apresentam-se as considerações finais, assim como as sugestões para estudos futuros.

\section{Referencial Teórico}

Num universo em mutação constante, em meio aos avanços da globalização, onde as organizações experimentam altos níveis de tecnologia, atendem um mercado bem mais exigente e precisam empregar pessoas com elevada qualificação, nos deparamos muitas vezes com cenários de insatisfação com o ambiente organizacional em seus diversos níveis. Enquanto as organizações preocupam-se em ser mais competitivas e buscam alcançar maiores produções a mínimos custos, os empregados buscam, no interior das empresas, a compensação do estresse causado pela busca frenética dos resultados esperados (FREITAS et al., 2016). O estresse ocupacional pode ser definido como um processo em que o indivíduo percebe demandas do trabalho como estressores, as quais, ao exceder sua habilidade de enfrentamento, provocam no sujeito reações negativas (PASCHOAL; TAMAYO, 2004, apud BALASSIANO; TAVARES; PIMENTA, 2011).

Quanto mais desenvolvida a sociedade, tanto mais complexas se tornam as organizações. Elas geram impacto sobre a qualidade de vida das pessoas, que passam a maior 
parte da vida convivendo entre suas paredes, sejam elas instituições educacionais, religiosas, políticas ou sociais, entre outras. E quanto mais crescem as organizações, mais necessitam de recursos e competências para permanecerem no mercado e garantirem sua sobrevivência (CHIAVENATO, 2009).

Durante muito tempo, ao se falar em qualidade nas empresas, enfatizava-se principalmente a produção dos empregados. Hoje, fala-se não apenas em qualidade no trabalho, mas também na qualidade de vida desses colaboradores. Assim, para que sejam produtivos, devem sentir que o trabalho que executam é adequado a suas habilidades e que são tratados como pessoas. "Não se pode esquecer que parte significativa da vida das pessoas é dedicada ao trabalho e que para muitas o trabalho constitui a maior fonte de identificação pessoal. É natural, portanto, que almejem identificar-se com seu trabalho" (GIL, 2008a, p. 46). Desse modo, o trabalho permanece sendo uma importante fonte de pesquisa e sua centralidade pode ser percebida na construção da identidade, assim como na realização pessoal e na saúde mental dos trabalhadores (FARIA et al., 2017).

O homem é um ser social que, com raras exceções, somente descobre plenamente sua potencialidade nas suas relações com os outros. A existência de acentuado isolamento social provoca solidão no ser humano, por isso ele busca adaptar-se aos grupos sociais, de trabalho e à sociedade de modo geral (BARBIERI, 2013).

Kanaane (2011) defende que o trabalho, sob a perspectiva sociológica, é elemento chave na formação de coletividades humanas muito diversas em seus tamanhos e funções. Do ponto de vista psicológico, o trabalho provoca diferentes graus de motivação e de satisfação no trabalhador, principalmente quanto à forma e ao meio no qual desempenha sua tarefa. O mesmo autor afirma que

Há de se considerar a importância do trabalho no destino individual, evidenciando, inclusive, sua importância como fator de equilíbrio psicológico. As relações que o indivíduo estabelece com a sociedade estão demarcadas pelas possibilidades e perspectivas originadas da posição ocupada no contexto social e na forma pela qual ele consegue exercer sua ação no respectivo contexto e, em especial, no ambiente profissional (KANAANE, 2011, p. 19).

Os brasileiros trabalham, conforme prevê a legislação trabalhista, entre 40 e 44 horas semanais, sem citar aqueles que, por algum motivo, excedem essa carga horária, o que transformaria o ambiente de trabalho em uma "segunda casa" (WEIDLICH, 2015). Excluindo o tempo reservado para dormir, pode-se concluir que os trabalhadores passam a maior parte do 
dia exercendo atividade profissional - incluindo o trajeto até o trabalho - cerca de $60 \%$ do tempo diário.

Esse fato nos dá sustentação para afirmar que estudos sobre QVT são atemporais e configuram-se em instrumentos que permitem acesso a novos caminhos, na busca de melhorias para o mundo do trabalho, tendo em vista que o ser humano ainda é a melhor e mais sofisticada "ferramenta" de que se dispõe para o adequado funcionamento das organizações.

Vale salientar ainda que a expressão "qualidade de vida no trabalho" pode ter várias interpretações, que representam uma variável que não afirma nem nega as condições em que vivem os empregados de uma empresa. Segundo Hackman e Suttle (1977), citados por Kanaane (2011), a qualidade de vida refere-se ao atendimento das necessidades do indivíduo, afetando atitudes pessoais e comportamentais, a criatividade, a vontade de inovar ou aceitar mudanças, a capacidade de adaptar-se às mudanças no ambiente de trabalho e o grau de motivação interna para o trabalho; são evidentemente fatores importantes para o alcance da produtividade, pois aumenta o prazer na ocupação do cargo e a valorização do trabalho.

A QVT pode ser compreendida também como "a aplicação concreta de uma filosofia que busca alterar aspectos do trabalho, a fim de criar uma situação mais favorável à satisfação das necessidades dos trabalhadores e ao aumento da produtividade organizacional" (KUROGI, 2008, p. 54). Em outras palavras, na abordagem de Walton, citado por Kurogi (2008), significa a humanização do trabalho, sendo considerada uma responsabilidade social da organização, pois envolve o atendimento às necessidades e às aspirações do trabalhador pela reestruturação do desenho de cargos e de novas formas de organizar o trabalho.

O conceito de QVT também pode ser subjetivo, à medida que envolve a percepção do indivíduo e da sua posição na vida, na cultura; e do sistema de valores nos quais vive, em relação aos seus objetivos, expectativas e padrões (ZWIELEWSKI; TOLFO, 2016). Essa conceituação vai ao encontro do que propõe Gil (2008a) ao afirmar que cada pessoa possui valores e expectativas diferentes, o que aumenta os desafios para a empresa e seus desafios organizacionais.

Schawartz (1994) apud Demo (2010) define valores como metas transituacionais desejáveis, variando em importância, e que servem de princípios na vida individual ou de uma entidade social. O gestor de pessoas deve estar atento a esses valores, preocupando-se em garantir aos empregados um ambiente de trabalho atraente e capaz de proporcionar-lhes a satisfação da maioria de suas necessidades individuais, já que é preciso garantir também que o 
empregado possa confiar na organização (GIL, 2008a). Assim, é preciso que a Gestão de Pessoas assuma um papel de liderança para ajudar a alcançar a excelência organizacional necessária para enfrentar desafios competitivos, tais como a globalização, a utilização das novas tecnologias e a gestão do capital intelectual, com suas inúmeras particularidades.

Wagner e Rollenbeck (2009) ainda asseveram que, considerando os altos custos associados à insatisfação e ao stress do trabalhador, identificar esses problemas deve ser parte importante da descrição de cargo de todo gerente. Uma vez identificado um problema, as intervenções devem ser dirigidas para a fonte do stress. Em todo caso, por uma série de razões, um programa contínuo e sistemático de pesquisa deve ser um componente destacado de qualquer estratégia de recursos humanos. No entanto "É fundamental que a organização que realiza a pesquisa esteja pronta a agir de acordo com os resultados" (WAGNER; ROLLENBECK, 2009, p. 137).

Hoje, reconhece-se que os empregados preferem trabalhar em empresas que oferecem qualidade de vida, ou seja, capazes de proporcionar segurança e contentamento. Assim, cabe à empresa cuidar para que o ambiente oferecido a seus empregados seja suficientemente motivador, se quiser manter seus empregados e não ter que lidar com problemas de alta rotatividade que afligem algumas instituições. Por isso Barbieri (2013, p. 87, grifo do autor) assevera que

\footnotetext{
Criar impacto em ambientes organizacionais requer competências emocionais, sociais e políticas para que possam materializar ações em um contexto de interesses conflitantes. A organização, para competir em ambientes complexos e altamente dinâmicos, necessita gerar excelência de pessoas, excelência organizacional e excelência estratégica. A excelência de pessoas e a organizacional têm que ser produzidas em forma associadas para que possam ser concretizadas. (...) fazem-se necessárias a excelência estratégica e a capacidade de questionar continuamente as regras do jogo.
}

Ademais, o comportamento humano move-se pelo desejo de atingir algum objetivo, ou seja, são as metas individuais ou coletivas que motivam as pessoas a realizarem determinadas ações (GIL, 2008a). Contudo, apesar de poder ter inúmeras atitudes, o estudo do comportamento organizacional foca somente naquelas relacionadas ao trabalho (ROBBINS, 2009). Trata-se da satisfação no trabalho, do envolvimento e do comprometimento com ele; "refere-se a um conjunto de sentimentos que um indivíduo nutre em relação ao seu trabalho" (ROBBINS, 2009, p. 24). 
A capacidade de uma pessoa de lidar com experiências de trabalho insatisfatórias ou estressantes aumenta quando há uma oportunidade de falar sobre problemas e queixas (WAGNER; ROLLENBECK, 2009). Além disso, quando organização e colaboradores olham na mesma direção, adquirem o poder visionário e os desafios são vencidos conjuntamente.

\begin{abstract}
Visões estão enraizadas na realidade presente, mas focam o futuro. Elas são realidades desejadas. (...) O magnetismo de uma visão é gerado pela integração de um indivíduo, com o propósito, os valores e a realidade única de uma organização. (...) Uma visão compartilhada une as pessoas, criando uma conexão entre diversas pessoas e atividades. (...) Pessoas que compartilham visões estão mais dispostas a assumir responsabilidades; elas estão mais dispostas a desafiar o que é convencional (BARBIERI, 2013, p. 150).
\end{abstract}

Ainda com relação às variáveis que determinam a satisfação no trabalho, Robbins (2009, p. 24) afirma que os fatores mais importantes seriam "um trabalho mentalmente desafiante, recompensas justas, condições de trabalho estimulantes e colegas colaboradores".

\title{
Metodologia
}

Por se tratar de um estudo bibliométrico, sua abordagem é qualitativa, considerando que o método da base lógica de investigação é indutivo. No método indutivo a generalização deve ser constatada a partir de fatos concretos suficientemente confirmadores dessa realidade (Gil, 2008b). Seu propósito é descritivo porque estuda as relações entre duas ou mais variáveis do fenômeno em questão sem manipulá-las (KÖCHE, 2011).

O conhecimento da bibliometria, ciência métrico-estatística, pressupõe que o conhecimento está sendo medido ou consultado para obter resultados significativos em prol da sociedade (BAHIA; SANTOS; BLATTMANN, 2011). Além de analisar o "quanto" se produz, os estudos bibliométricos podem ser utilizados para investigar "o que" se produz, ou seja, são bússolas temáticas para os pesquisadores, apontando, por exemplo, a coerência entre propostas previamente estabelecidas e suas efetivas ações para a produção científica (VIEIRA; SANNA, 2013).

No presente estudo a fonte de pesquisa utilizada foi o Portal de Periódicos da Capes, uma das maiores bibliotecas virtuais do Brasil, que reúne e disponibiliza boa parte da produção científica nacional e internacional. Segundo informações disponíveis no Portal, ele conta com 
um acervo de mais de 38 mil títulos com texto completo, 134 bases referenciais, 11 bases dedicadas exclusivamente a patentes, além de livros, enciclopédias e obras de referência, normas técnicas, estatísticas e conteúdo audiovisual. Neste estudo foram selecionados apenas artigos, "modalidade de comunicação científica que costuma apresentar os resultados de pesquisa mais recentes" (BHONA et al., 2011, p. 90). Na seleção de busca foi utilizado o descritor "qualidade de vida no trabalho" em qualquer parte do texto, que retornou 368 documentos. Com a finalidade de refinar a pesquisa, foi realizada uma busca avançada, onde foram selecionados apenas os artigos publicados em português, no período de 2007 a 2017, e advindos somente de periódicos revisados por pares. Com isso, o corpus inicial totalizou 116 artigos. No entanto, observou-se que alguns desses trabalhos não tratavam da temática Qualidade de Vida no Trabalho como assunto principal, assim eles foram excluídos do corpus final, o qual totalizou 49 artigos.

A análise de conteúdo dos artigos foi realizada considerando os seguintes aspectos: ano de publicação; autor(es), suas regiões de origem e maior titulação acadêmica; assuntos que aparecem relacionados com o tema QVT; periódicos de publicação; as principais metodologias adotadas e os principais referenciais teóricos utilizados nas pesquisas.

Para a demonstração gráfica dos dados foram utilizados o Microsoft Excel e a ferramenta on-line gratuita wordclouds. A fim de realizar o cálculo dos autores mais citados nas referências bibliográficas dos artigos analisados foi efetuada a contagem por obra citada e contabilizou-se, nessa categoria, apenas os primeiros autores de cada trabalho analisado.

\section{Descrição e Análise dos Resultados}

Ao analisar a quantidade de artigos produzida no período estudado, de 2007 a 2017 , verificou-se que os anos de 2008 e 2010 apresentaram maior quantidade de produção acadêmica, enquanto o ano de 2011 obteve a quantidade mínima. Notou-se também um aumento na produção em 2012, posterior diminuição em 2013, estabilidade entre os anos de 2014 e 2016, e uma sutil elevação no ano de 2017, conforme observa-se no Gráfico 1. 
Gráfico 1 - Publicações sobre Qualidade de Vida no Trabalho por ano

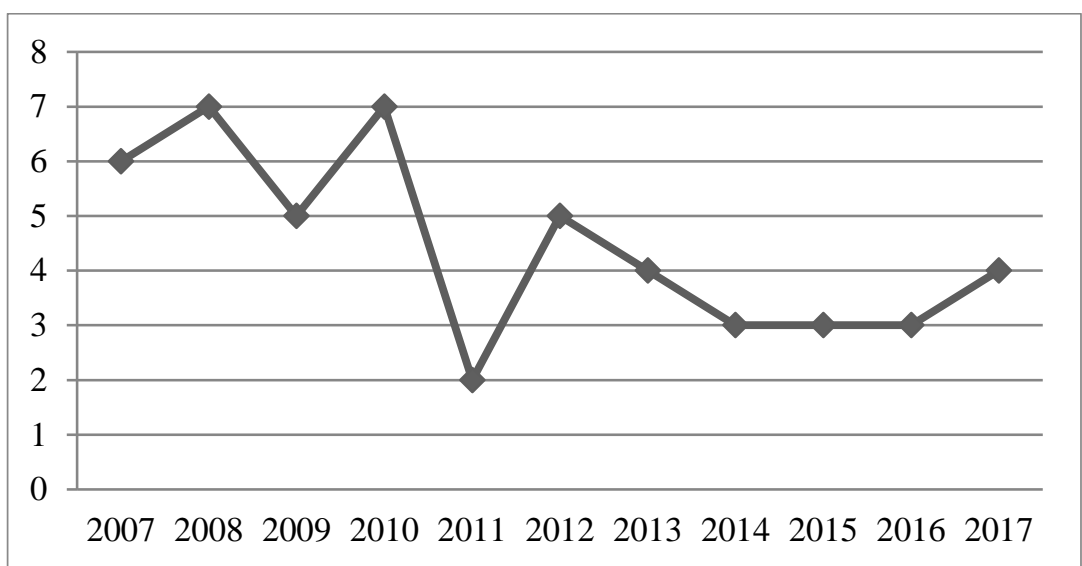

Fonte: dados da pesquisa (2018)

Através de consultas aos currículos dos autores na Plataforma Lattes do Conselho Nacional de Desenvolvimento Científico e Tecnológico $(\mathrm{CNPq})$, foi possível verificar a distribuição geográfica de suas instituições de origem, disposta no Gráfico 2. Constatou-se que há concentração de autorias nos Estados do Sul e Sudeste (aproximadamente 78\% dos autores), seguidos pelas regiões Nordeste (17\%), Norte (3\%) e Centro-Oeste (2\%).

Gráfico 2 - Distribuição dos Autores por Região do Brasil

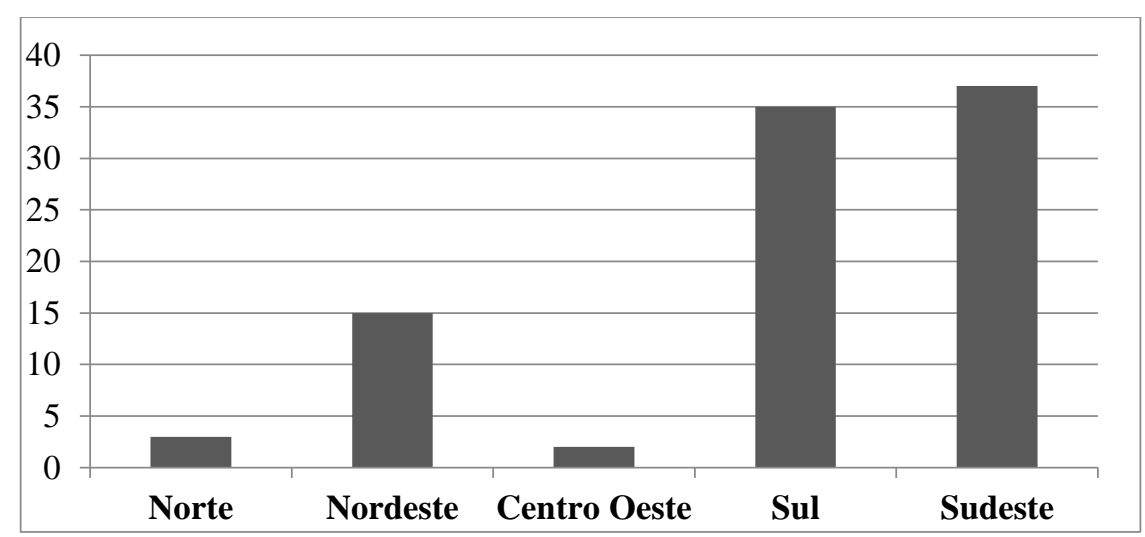

Fonte: dados da pesquisa (2018)

Quanto à maior titulação dos autores, observou-se que o doutorado é o nível predominante. Aproximadamente $66 \%$ dos autores possui essa formação, ao passo que os mestres ocupam a segunda colocação, com 21\%, seguidos pelos especialistas, os pósdoutorados e os graduados. 
Os autores com maior produção científica sobre QVT, durante o período em estudo, estão apresentados no Quadro 1, onde se constata que os autores mais prolíferos pertencem a instituições das regiões Sul e Sudeste do país, com uma única exceção de autoria para a região Nordeste. Vale ressaltar que existem 12 grupos de pesquisa no $\mathrm{CNPq}$ que pesquisam sobre o tema.

\begin{tabular}{|c|c|c|} 
Quadro 1 - Publicações por autor \\
\begin{tabular}{|c|c|c|}
\hline Autor & UF de origem & $\mathbf{N}^{\mathbf{0}}$ de Artigos \\
\hline Ana Cristina Limongi-França & São Paulo & 04 \\
\hline Antônio Carlos de Francisco & Paraná & 03 \\
\hline Denise Rodrigues Costa Schmidt & Paraná & 03 \\
\hline Bruno Pedroso & Paraná & 02 \\
\hline Gustavo Luis Gutierrez & São Paulo & 02 \\
\hline Jássio Pereira de Medeiros & Rio Grande do Norte & 02 \\
\hline Luciana Alves & *Indisponível & 02 \\
\hline Luciana da Silva Timossi & *Indisponível & 02 \\
\hline Lúcio Flávio Renault de Moraes & Minas Gerais & 02 \\
\hline Luis Paulo Bresciani & São Paulo & 02 \\
\hline Luiz Alberto Pilatti & Paraná & 02 \\
\hline Natalia Tostes & São Paulo & 02 \\
\hline Nilo Sergio Guidelli & São Paulo & 02 \\
\hline Rosana Aparecida Spadoti & São Paulo & 02 \\
\hline
\end{tabular}
\end{tabular}

*Currículos não localizados na Plataforma Lattes.

Fonte: dados da pesquisa (2018)

Notou-se neste estudo que os periódicos de publicação dos artigos são diversificados, contudo há predominância de publicações em periódicos das áreas de Administração (45\%) e Saúde (31\%) das produções. O Quadro 2 aponta os periódicos que mais publicaram sobre o assunto em questão.

Quadro 2 - Publicações por periódico

\begin{tabular}{|l|c|c|}
\hline \multicolumn{1}{|c|}{ Periódicos } & Frequência & $\%$ \\
\hline Demais Periódicos* & 33 & 67,3 \\
\hline ACTA Paulista de Enfermagem & 3 & 6,1 \\
\hline Diálogo & 2 & 4,0 \\
\hline HOLOS & 2 & 4,0 \\
\hline Rege: Revista de Gestão & 2 & 4,0 \\
\hline Revista Brasileira de Enfermagem & 3 & 6,1 \\
\hline Revista Ibero-Americana de Estratégia & 2 & 4,0 \\
\hline Revista Organizações em Contexto & 2 & 4,0 \\
\hline
\end{tabular}

*Com frequência de publicação igual a um

Fonte: dados da pesquisa (2018) 
Foram analisados também os principais construtos relacionados com o tema proposto, descritos no Quadro 3, onde é apresentada a frequência com que o descritor foi encontrado nas palavras-chave dos artigos verificados.

Quanto às metodologias adotadas nos trabalhos estudados, percebeu-se forte tendência à abordagem qualitativa, seguida da quantitativa e da quali-quantitativa. É cada vez mais comum a condução de pesquisas científicas orientadas pela tônica qualitativa. A avaliação qualitativa é caracterizada pela descrição, compreensão e interpretação de fatos e fenômenos, em contrapartida à quantitativa, onde predominam mensurações (MARTINS; THEÓPHILO, 2007).

Quadro 3 - Construtos vinculados à QVT

\begin{tabular}{|c|c|}
\hline Descritor & Frequência \\
\hline Enfermagem & 6 \\
\hline Satisfação & 6 \\
\hline Saúde & 6 \\
\hline Professor / Docente & 5 \\
\hline Recursos humanos & 5 \\
\hline Administração (Gestão) Pública & 3 \\
\hline Ergonomia & 3 \\
\hline Estresse & 3 \\
\hline Organizacional & 3 \\
\hline Público & 3 \\
\hline Educação & 2 \\
\hline Inovação & 2 \\
\hline Modelo de Walton & 2 \\
\hline Profissional & 2 \\
\hline Programas & 2 \\
\hline Projetos & 2 \\
\hline Responsabilidade social & 2 \\
\hline Síndrome de Burnout & 2 \\
\hline
\end{tabular}

Fonte: dados da pesquisa (2018)

Os tipos de pesquisa predominantes foram os estudos exploratório-descritivos combinados. Essa combinação tem por objetivo "descrever completamente determinado fenômeno, como por exemplo o estudo de um caso para o qual são realizadas análises empíricas e teóricas” (MARCONI; LAKATOS, 2007, p. 85). Dentre os trabalhos que explicitaram sua abordagem de pesquisa, o estudo de caso destacou-se em mais de $40 \%$ das produções. Em segundo lugar ficaram os estudos descritivos, seguidos dos exploratórios e dos descritivoexplicativos.

Quanto aos instrumentos utilizados para a coleta de dados, os questionários foram os mais utilizados pelos pesquisadores, seguidos das entrevistas, majoritariamente semi- 
estruturadas, e da observação direta. Alguns autores lançaram mão de mais de um instrumento para a coleta das informações.

Para a análise dos dados obtidos em suas pesquisas, a maioria dos estudiosos utilizou a técnica de análise de conteúdo, sendo cerca de 50\% das análises baseadas em Bardin (1977). Essa técnica desenvolve-se com a finalidade de descrever, sistematicamente, o conteúdo das comunicações, que levam a resultados quantitativos (MARCONI; LAKATOS, 2007).

Com a finalidade de chegar aos dados quantitativos, a análise estatística descritiva foi a mais utilizada nos trabalhos estudados, seguida de análise de correlação uni e multivariada; análise fatorial; análise de variância (ANOVA) e análise temática. De acordo com Martins e Theóphilo (2007), a estatística descritiva envolve a organização, sumarização e descrição de dados. O software mais utilizado para tratamento dos dados foi o programa estatístico Statistical Package for the Social Science (SPSS), sendo esta uma ferramenta consolidada nesse campo e comum entre administradores, estudantes e pesquisadores (MARTINS; THEÓPHILO, 2007).

Percebeu-se forte presença de referenciais teóricos estrangeiros nas publicações estudadas. Mesmo assim, a líder de citações (40) é a professora Ana Cristina Limongi-França, Universidade de São Paulo (USP), e Fundadora da Associação Brasileira de Qualidade de Vida - ABQV.

Entre os escritores estrangeiros, o líder em referências é o autor Richard J. Walton, professor e jornalista americano, criador do reconhecido "Modelo de Walton", que apresenta questionamentos relevantes a serem abordados na pesquisa sobre Qualidade de Vida no Trabalho. "O modelo de Walton (1973), mesmo considerando-se sua anterioridade, é um dos mais aceitos e utilizados por pesquisadores brasileiros" (TIMOSSI et al., 2009, p. 396).

\section{Conclusões}

A pesquisa teve o intuito de identificar os aspectos que vem marcando os estudos referentes à temática da Qualidade de Vida no Trabalho (QVT). As evidências científicas apontaram que as publicações sobre o tema vêm diminuindo ao longo dos últimos anos em relação aos anos iniciais da linha temporal deste trabalho, talvez por se tratar de um assunto já abundantemente discutido. Posto que a relação entre QVT e inovação foi pouco significativa entre os artigos analisados, pode estar aí uma boa oportunidade de pesquisa. 
Quanto à avaliação da satisfação dos colaboradores em relação ao seu ambiente de trabalho, destacaram-se as categorias dos docentes e dos profissionais de enfermagem, conforme pôde-se observar nos construtos encontrados. Isso pode instigar os pesquisadores ao seguinte questionamento: será que as áreas de educação e saúde são as que demandam maior nível de stress e (in)satisfação das pessoas no trabalho? Por quê? Estudos posteriores sobre a temática podem contribuir para essa investigação.

Dentre as variáveis citadas por Robbins (2009) que poderiam atender às necessidades de satisfação no trabalho, não foram encontrados descritores referentes ao trabalho mentalmente desafiante, recompensas justas, condições de trabalho estimulantes e colegas colaboradores, no entanto algumas dessas variáveis puderam ser encontradas em parte dos artigos analisados, principalmente aquelas que se referem às condições adequadas de trabalho num ambiente física e mentalmente saudável. Além disso, a amostragem utilizada nesse estudo coloca como limitação na seleção de publicações para esta revisão a seleção dos artigos apenas em língua portuguesa.

Assim, constatou-se que o tema estudado é de grande relevância para a sociedade, pois as pessoas são o cérebro e o coração das organizações, sendo elas que as movem e sustentam. Enquanto seres importantes que são, precisam ser zeladas e incentivadas a crescer profissionalmente e, por que não, emocionalmente no seu ambiente laboral. Logo, espera-se que este estudo possa contribuir para futuras investigações no âmbito da QVT, baseadas nas conexões sugeridas e demais indicadores que possam ser inspirados nesse trabalho.

\section{Referências}

BAHIA, E. M. S.; SANTOS, R. N. M.; BLATTMANN, U. Ergonomia: estudo bibliométrico na base LISA. Biblios, v. 42, Jan-Mar. 2011.

BALASSIANO, M.; TAVARES, E.; PIMENTA, R. C. Estresse ocupacional na administração pública brasileira: quais os fatores impactantes? Revista de Administração Pública - Rio de Janeiro, v. 45, n. 3, p. 751-74, Mai-Jun. 2011.

BARBIERI, U. F. Gestão de pessoas nas organizações: a aprendizagem da liderança e da inovação. São Paulo: Atlas, 2013. 
BHONA, F. M. C.; LOURENÇO, L. M.; BRUM, C. R. S. Violência doméstica: um estudo bibliométrico. Arquivos Brasileiros de Psicologia. Rio de Janeiro, v. 63, n. 1, p. 1-110, 2011.

CHIAVENATO, I. Administração de recursos humanos: fundamentos básicos. 7. ed. Barueri, SP: Manole, 2009.

DEMO, G. Políticas de gestão de pessoas nas organizações: papel dos valores organizacionais e da justiça organizacional. $3^{\text {a }}$ edição. São Paulo: Atlas, 2010.

FARIA, Renata Mercês Oliveira de; LEITE, Isabel Cristina Gonçalves; SILVA, Girlene Alves da. Physis Revista de Saúde Coletiva, Rio de Janeiro, 27 [ 3 ]: 541-559, 2017.

FREITAS, A. J. ; SILVA JUNIOR, E. G.; REINALDO, H. O. A.; GOMES, M. L. F.; ARRUDA, S. C. Qualidade de vida no trabalho e saúde e segurança ocupacional em uma organização da construção civil. Revista Gestão Organizacional. v. 9, n. 2 - Mai-ago. 2016.

GIL, C. A. Gestão de pessoas: enfoque nos papéis profissionais. São Paulo: Atlas, 2008a.

GIL, C. A. Métodos e técnicas de pesquisa social. 6. ed. São Paulo: Atlas, 2008b.

KANAANE, R. Comportamento Humano nas Organizações: o homem rumo ao século XXI. 2. ed. São Paulo: Atlas, 2011.

KÖCHE, J. C. Fundamentos de metodologia científica: teoria da ciência e iniciação à pesquisa. Petrópolis, RJ: Vozes, 2011.

KUROGI, M. S. Qualidade de vida no trabalho e suas diversas abordagens. Revista de Ciências Gerenciais, Londrina, v. 12, n. 16, p. 49-62, 2008.

MARCONI, M. A.; LAKATOS, E. M. Técnicas de pesquisa: planejamento e execução de pesquisas, amostragens e técnicas de pesquisa, elaboração, análise e interpretação de dados. 6 . ed. São Paulo: Atlas, 2007.

MARTINS, G. A.; THEÓPHILO, C. R. Metodologia da investigação científica para ciências sociais aplicadas. São Paulo: Atlas, 2007.

ROBBINS, S. P. Fundamentos do comportamento organizacional. 8. ed. São Paulo: Pearson Prentice Hall, 2009.

SANT'ANNA, A. S.; MORAES, L. F. R. O movimento de qualidade de vida no trabalho: um estudo de suas origens, evolução, principais abordagens e avanços no Brasil. Belo Horizonte: CEPEAD-UFMG, 1998.

SLOMSKI, V. G.; PINHEIRO, I. C. B.; MEGLIORINI, E.; FERREIRA, T. A. R. C. A importância da formulação da questão de pesquisa na produção científica em contabilidade: uma discussão a partir de trabalhos publicados no Congresso Brasileiro de Custos no ano de 
2009. Congresso Brasileiro de Custos, 20, 2013, Uberlândia. Anais... São Leopoldo: Associação Brasileira de Custos, 2013.

TAVARES, M. O.; LIMACHI, I. G. T. Avaliação da Qualidade de Vida no Trabalho: Estudo de Caso em duas Escolas Particulares no Cariri Cearense. Id onLine Revista Multidisciplinar e de Psicologia, 2017, v. 11, n. 38, p. 127-149. ISSN: 1981-1179.

TIMOSSI, L. S. ; PEDROSO, B. ; PILATTI, L. A.; FRANCISCO, A. C. Adaptação do modelo de Walton para avaliação da qualidade de vida no trabalho. Revista da Educação Física/UEM. Maringá, v. 20, n. 3, p. 395-405, 3. trim. 2009.

VIEIRA, R. Q.; SANNA, M. C. O uso do estudo bibliométrico pelos pesquisadores da saúde em periódicos científicos digitais brasileiros. Congresso Brasileiro de Biblioteconomia, Documentação e Ciência da Informação. 25. 2013. Florianópolis, SC - Brasil. Anais... Florianópolis-SC, 2013.

WAGNER III, J. A.; HOLLENBECK, J. R. Comportamento Organizacional: Criando vantagem competitiva - 2. ed. São Paulo: Saraiva, 2009.

WEIDLICH, P. Como passamos muitas horas, trabalho é como a segunda casa. Disponível em: <http://www.tribunapr.com.br/arquivo/mulher/como-passamos-muitas-horas-trabalho-ecomo-a-segunda-casa/>. Acesso em: 28 mai. 2018.

ZWIELEWSKI, G.; TOLFO, S. R. Qualidade de vida no trabalho de profissionais expatriados para Índia e China. Revista de Administração - REAd. v. 84, n. 2, mai-ago. 2016 - p. 510 542.

Como citar este artigo (Formato ABNT):

MANDÚ, Maria Jaqueline da S.; CORREIA NETO, Jorge da S.; SOUZA JÚNIOR, Marcílio Ferreira de. Qualidade de Vida no Trabalho: um Estudo Bibliométrico da Pesquisa em Português. Id on Line Revista Multidisciplinar e de Psicologia, 2018, vol.12, n.40, p.1114-1128. ISSN: 19811179.

Recebido: 28.05.2018

Aceito: 29.05 .2018 